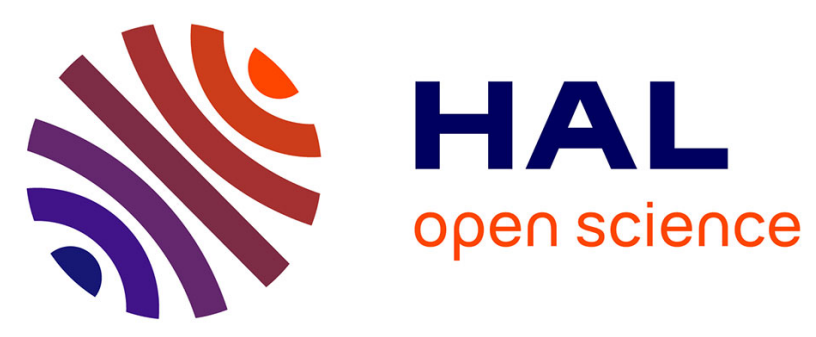

\title{
Novel Nanostructured Lipid Carrier Co-Loaded with Doxorubicin and Docosahexaenoic Acid Demonstrates Enhanced in Vitro Activity and Overcomes Drug Resistance in MCF-7/Adr Cells
}

Samuel V Mussi, Rupa Sawant, Federico Perche, Mônica C Oliveira, Ricardo

B Azevedo, Lucas a M Ferreira, Vladimir P Torchilin

\section{To cite this version:}

Samuel V Mussi, Rupa Sawant, Federico Perche, Mônica C Oliveira, Ricardo B Azevedo, et al.. Novel Nanostructured Lipid Carrier Co-Loaded with Doxorubicin and Docosahexaenoic Acid Demonstrates Enhanced in Vitro Activity and Overcomes Drug Resistance in MCF-7/Adr Cells. Pharmaceutical Research, 2014, 31 (8), pp.1882 - 1892. 10.1007/s11095-013-1290-2 . hal-02995777

\section{HAL Id: hal-02995777 \\ https://hal.science/hal-02995777}

Submitted on 3 Dec 2020

HAL is a multi-disciplinary open access archive for the deposit and dissemination of scientific research documents, whether they are published or not. The documents may come from teaching and research institutions in France or abroad, or from public or private research centers.
L'archive ouverte pluridisciplinaire HAL, est destinée au dépôt et à la diffusion de documents scientifiques de niveau recherche, publiés ou non, émanant des établissements d'enseignement et de recherche français ou étrangers, des laboratoires publics ou privés. 


\section{Novel nanostructured lipid carrier co-loaded with doxorubicin and docosahexaenoic acid demonstrates enhanced in vitro activity and overcomes drug resistance in MCF-7/Adr cells}

Samuel V. Mussi ${ }^{1,2}$, Rupa Sawant ${ }^{2}$, Federico Perche ${ }^{2}$, Ricardo B. Azevedo $^{3}$, Lucas A.M. Ferreira ${ }^{1}$ and Vladimir P. Torchilin ${ }^{2 *}$

${ }^{1}$ Department of Pharmaceutics, Faculty of Pharmacy, Federal University of Minas Gerais (UFMG), Av Antônio Carlos, 6627, Campus Pampulha, , Belo Horizonte, Minas Gerais, 31270-901, Brazil

${ }^{2}$ Center for Pharmaceutical Biotechnology and Nanomedicine, 360 Huntington Avenue, 140 The Fenway, Northeastern University, Boston, MA 02115, USA

${ }^{3}$ Department of Genetic and Morfology, Instituto de Ciências Biológicas, Universidade de Brasília, Brasília-DF, 70910-900, Brazil

* Corresponding author. Tel.: +1 617373 3206; Fax: +1 6173737509.

E-mail address: v.torchilin@neu.edu (V.P. Torchilin).

\section{Abstract}

Aim: To develop a new nanostructured lipid carrier (NLC) co-loaded with doxorubicin and docosahexaenoic acid (DHA) for combination therapy to evaluate the in vitro activity in drug sensitive and resistant cancer cell lines.

Methods: The NLC was prepared by a hot homogenization method and they were characterized by size, zeta potential, entrapment efficiency and drug loading. The drug release was evaluated by dialysis in DMEM and NLC aggregation was assayed for in the presence of serum. The cytotoxicity of formulations and drug uptake were evaluated in a cell monolayer model with sensitive MDA-MB-231, MCF-7 and maybe? the doxorubicin-resistant variant MCF-7/Adr as monolayers or spheroid cultures the drug resistant MCF-7/Adr cell lines and in spheroids of MCF7/Adr. 
Results: The formulation obtained had a size of about $80 \mathrm{~nm}$ and a negative charge of-zeta potential. The NLC loaded with doxorubicin and DHA showed the same activity as free drugs against MCF-7, slightly higher activity for MDA-MB-231 and much stronger activity against MCF-7/Adr. Maybe similar on sensitive, higher resistant? The doxorubicin uptake of free and encapsulated drug was similar for sensitive cell lines and higher for the resistant, suggesting a bypassing of the Pglycoprotein pump bomb efflux by NLC. For spheroids, the NLC loaded with doxorubicin and DHA showed stronger activity that may be explained by the greater penetration of the formulation into the spheroids structure and the combination of the respective drugs. The higher activity of NLC in spheroids was correlated with increased drug penetration than free doxorubicin? These findings suggest that the combination of doxorubicin and DHA improves of the drugs activity and that their co-encapsulation in NLC shows higher efficacy, being a promising alternative for cancer therapy in sensitive and resistant cell lines?

\section{Introduction}

Doxorubicin is an anthracycline with broad-spectrum anticancer activity that is widely used in cancer therapy but has serious side effects highlighted by potentially fatal cardiotoxicity (Livi et al, 2009; Shi et al, 2011). The low tumor penetration and limited distribution in solid tumors are the main causes of its failures as a therapeutic agent (Primeau et al., 2005; Trédan et al., 2007)could add Lankelma doxorubicin gradients. Anthracycline-based combination chemotherapy regimens have shown ... Combination of anthracycline-based chemotherapy has shown improvement in activity compared to a single anthracycline, including combined doxorubicin or epirubicin with cyclophosphamide; doxorubicin, cyclophosphamide, and fluorouracil; epirubicin with cyclophosphamide and fluorouracil. However, despite greater activity, they these regimens are also more toxic than single agent regimens (Jassem et al, 2001; Livi et al, 2009).

Alternatively, the combination of docosahexaenoic acid (DHA) and doxorubicin has been described to increase the sensitivity of tumors to chemotherapy compared to the single doxorubicin (Germain et al. 1998; Colas et 
al., 2006; Siddiqui et al., 2011). DHA is a long-chain (C22) polyunsaturated fatty acid (Omega 3 ) that enhances oxidative stress and subsequent lipid peroxidation of tumor cells (Mahéo et al, 2005). Several studies have reported an increase in the sensitivity of mammary tumors in rodents to doxorubicin when accompanied by a prolonged supplementation with DHA (Hardman et al., 2001; Colas et al., 2006;) and others have verified that this is probably due to the increased level of oxidative stress specifically in cancer cells (Hajjaji et al, 2012). In addition, the literature suggests that DHA attenuates drug resistance and improves anticancer drug efficacy in resistant cell lines (Mahéo et al, 2005; Siddiqui et al, 2011). Recently, a phase II trial verified that a dietary DHA supplementation improved the outcome of chemotherapy in metastatic breast cancer patients (Bougnoux et al., 2009). However, the varieties of drug administration schedules have complicated the management of the pharmacokinetic and pharmacodynamic profiles and the obtention of obtain a uniform temporal and spatial codelivery (co-delivery?) is challenging (Atu-027, CPX) pratically impossible. Thus, the combination drugs using drug delivery systems (DDSs) emerges as an attractive alternative (Storniolo et al, 2008) (Parhi, nanotechnology-based combinatorial drug delivery?.

DDSs based on approaches in nanobiotechnology DDSs-based combination therapy? offer many advantages, such as more synchronized and controlled pharmacokinetics of the drugs, resulting in improved drug efficacy, with a single formulation with improved solubility and bioavailability, with a predominantly endocytotic uptake and the potential to bypass mechanisms of multidrug resistance (Okuda and Kidoaki, 2012). Among these DDSs, liposomes, polymeric micelles, solid lipid nanoparticles (SLNs), nanostructured lipid carrier (NLC) have been described. Some DDSs have reached the market, e.g. liposomal doxorubicin. Such nanocarriers with sizes in a range 50-200 nm enhance the concentration of drugs in the tumor by a mechanism known as the "enhanced permeability and retention (EPR) effect" (Maeda et al. 2000; Torchilin, 2011; Li et al., 2012).

The current NLC represent an improved generation of SLNs that consist of solid lipid matrices with spatially distributed liquid lipids, resulting in a structure with imperfections in the crystal structure that accommodate the drug. NLC and SLN? They share advantages including biocompatibility and the possibility of production 
on an industrial scale since they do not require the use of organic solvents and their similarity to parenteral nutrition manufacturing methods. Contrary to nanoemulsions, the drug release from NLC can be finely tuned by the nature of matrix liquid lipids? Additionally, NLC is are capable of control the release that nanoemulsions can not offer due to their nature of matrix liquid lipids (Mehnert and Mäder, 2001; Müller et al., 2002; Wissing et al., 2004). However, the entrapment of hydrophilic drug, such as doxorubicin, in these lipid systems is usually low. The formation of an ion pairing with a lipophilic contra-ion has been proposed as an alternative to increase the drug encapsulation (Serpe et al. 2004; Wong et al., 2006; Mussi et al, 2013).

In this work our aim was to develop a new lipid formulation loaded with doxorubicin combined with DHA triglyceride (lipid liquid) as a means an alternative to obtain a NLC with enhanced doxorubicin activity, evaluate the formulation physicochemical characteristics, drug release and the in vitro efficacy in sensitive and resistant human breast cancer cell lines in cell monolayer and spheroid models.

\section{Materials and Methods}

\subsection{Materials}

Doxorubicin hydrochloride was purchased from ACIC Chemicals (Ontario, Canada). Doxorubicin hydrochloride liposome injection (Lipodox®) was purchased from Sun Pharma Global FZE (Gujarat, India). Triethanolamine (TEA), oleic acid $(\mathrm{OA})$, ethylenediamine tetraacetic acid sodium (EDTA) were purchased from Sigma-Aldrich (Missouri, USA). Glyceryl behenate (Compritol 888 ATO®) was kindly provided by Gattefossé (Rhône-Alpes, France). Monooleate of sorbitan ethoxylated (Super refined ${ }^{\mathrm{TM}}$ polysorbate 80; Tween $^{\mathrm{TM}}$ 80) and docosahexaenoic acid (DHA) as triglyceride (Incromega ${ }^{\text {TM }}$ DHA 500TG) were kindly provided by Croda Inc. (New Jersey, USA). Dulbecco's Modified Eagle Medium (DMEM), antibiotic stock solution (10,000 I.U. of penicillin $+10,000 \mu \mathrm{g} / \mathrm{mL}$ of streptomycin) and $0.25 \%$ Trypsin-EDTA were purchased from CellGro (Virginia, USA). Heat inactivated fetal bovine serum (FBS) was purchased from Atlanta Biologicals 
(Georgia, USA). The Cell Titer Blue assay kit and CytoTox 96® Non-Radioactive Cytotoxicity Assay were purchased from Promega (Wisconsin, USA). All other chemicals were of analytical grade.

\subsection{Preparation of formulation}

The formulation was prepared by the hot melting homogenization method using emulsification-ultrasound and the composition was described previously with some modifications (Mussi et al., 2013). The DHA was used in triglyceride form (Incromega® DHA 500 TG). The formation of an ionic pairing to promote the doxorubicin encapsulation was obtained with oleic acid. Briefly, for a batch of $10 \mathrm{ml}$ of formulation, the oily phase (OP) was prepared with $100 \mathrm{mg}$ of Tween $80,10 \mathrm{mg}$ of oleic acid, $5 \mathrm{mg}$ of doxorubicin, $6 \mathrm{mg}$ of triethanolamine and $150 \mathrm{mg}$ of matrix lipid composed of $110 \mathrm{mg}$ of Compritol and $40 \mathrm{mg}$ of $\mathrm{DHA}(0.4 \% \mathrm{w} / \mathrm{v})$. The aqueous phase (AP) was composed of $4 \mathrm{mg}$ of EDTA and $6 \mathrm{~mL}$ of purified water. This formulation was named NLC-DHA $0.4 \%$. A control NLC was prepared loading doxorubicin and a liquid lipid with low amount of unsaturated lipids (peanut oil) at $0.4 \%$. After the preparation the volume was adjusted to $10 \mathrm{~mL}$ using a volumetric cylinder. First, the OP and the AP were heated separately to $80^{\circ} \mathrm{C}$. After OP melting at $80^{\circ} \mathrm{C}$, the $\mathrm{AP}$ was gently dropped into the $\mathrm{OP}$ and homogenized using a glass rod for $1 \mathrm{~min}$. This emulsion was immediately subjected to high intensity probe sonication (8 watts) for 5 minutes, using a high intensity ultrasonic processor (Fisher F60 Sonic Dismembrator Fisher F-6; Fisher Scientific, Pennsylvania, USA). The $\mathrm{pH}$ was adjusted to 7.0 with $0.1 \mathrm{M} \mathrm{HCl}$ and $0.1 \mathrm{M} \mathrm{NaOH}$. The formulation was stored at $4^{\circ} \mathrm{C}$, protected from light under in a nitrogen atmosphere. To evaluate the influence of the lipid matrix on the release of doxorubicin, two additional formulations loaded with doxorubicin were prepared: NLC containing DHA at $0.8 \%$ (NLC-DHA $0.8 \%$ ) and a nanoemulsion (NE) containing only $1.5 \%$ DHA as the lipid matrix (NE-DHA 1.8\%).

\subsection{Characterization of the formulations}

The mean particle diameter and zeta potential were measured by dynamic light scattering (DLS) and electrophoretic mobility, respectively, using the Zeta 
PLUS particle size analyzer (Brookhaven Instruments; Brookhaven, USA). All measurements were performed in triplicate.

The encapsulation efficiency (EE) and drug loading (DL) of doxorubicin in NLC were determined by an ultrafiltration method using centrifugal devices (Amicon ${ }^{\circledR}$ Ultra - $0.5 \mathrm{~mL} 100 \mathrm{k}$; Millipore, USA) with the membrane passivated with a $5 \%$ aqueous solution of Tween $^{\mathrm{TM}} 20$ to eliminate doxorubicin binding as previously described (Mussi et al., 2013). The EE and DL were calculated using the following equations:

$$
\begin{aligned}
& \mathrm{EE}_{(\%)}=\left(\mathrm{C}_{\mathrm{T}}-\mathrm{C}_{\mathrm{Ap}}\right) / \mathrm{C}_{\mathrm{T}} \times 100 \\
& \mathrm{DL}_{(\mathrm{m} / \mathrm{g})}=\mathrm{W}_{\mathrm{DL}} / \mathrm{W}_{\mathrm{NP}}
\end{aligned}
$$

Where, $\mathrm{C}_{\mathrm{T}}=$ total doxorubicin concentration in NLC, $\mathrm{C}_{\mathrm{AP}}=$ doxorubicin concentration in aqueous phase (non-encapsulated), $\mathrm{W}_{\mathrm{DL}}=\mathrm{mg}$ of drug loaded in nanoparticles and $\mathrm{W}_{\mathrm{NP}}=\mathrm{g}$ of nanoparticles (lipids).

Briefly, the $\mathrm{C}_{T}, \mathrm{C}_{\mathrm{AP}}$ and $\mathrm{W}_{\mathrm{DL}}$ were evaluated as follows. The $\mathrm{C}_{T}$ was analyzed dissolving an aliquot of the NLC dispersion in a mixture of tetrahydrofuran (THF)/methanol (MeOH) 4:6 v/v, centrifugation for $10 \mathrm{~min}$ at 2,400 $\mathrm{g}$ and analysis of the supernatant by spectrophotometry at 480/x nm (UV-mini 1240; Shimadzu, Japan). The $\mathrm{C}_{\mathrm{AP}}$ was evaluated from an aliquot of the aqueous phase separated from the NLC dispersion by ultrafiltration (10 min at 2,400g), dilution with $\mathrm{THF} / \mathrm{MeOH}$ and analysis by UV-vis. The $\mathrm{W}_{\mathrm{DL}}$ was calculated using the calculated EE $x$ mg total of doxorubicin added.

\subsection{Serum stability}

Serum stability of NLC was investigated by incubating the NLC with FBS 1:1 at $37^{\circ} \mathrm{C}$ with shaking $(250 \mathrm{rpm})$ for up to $24 \mathrm{~h}$. Samples were collected, diluted in purified water and the measurement of zeta potential and size performed using the Zeta Plus Analyzer.

\subsection{Release of doxorubicin from NLC}

The release study was conducted by dialysis in DMEM containing $10 \%$ fetal bovine serum (adapted from Elbayoumi and Torchilin, 2008). Dialysis tubes with a cutoff size of $100 \mathrm{KDa}$ (Cellulose ester membrane; Spectrum Laboratories; Rancho 
Dominguez, USA) were filled with $3 \mathrm{~mL}$ of formulations loaded with doxorubicin or doxorubicin aqueous solution $(0.5 \mathrm{mg} / \mathrm{mL})$ diluted in the media $1: 2$, sealed and incubated with $50 \mathrm{ml}$ of the media for up to $48 \mathrm{~h}$ at $37^{\circ} \mathrm{C}$, with continuous shaking at 250 RPM. At various time points, aliquots were withdrawn, replaced with an equal volume of the media. The doxorubicin concentrations were measured by a spectrofluorimetric method using the Synergy HT Multi-Mode Microplate Reader (Biotek; Winnooski,USA) with 485/590 ex/em wavelengths. The values were plotted as percentage of cumulative drug release accumulated released drug.

\subsection{Cell culture}

MDA-MB-231 and MCF-7 were purchased from The American Type Culture Collection (ATCC; Manassas, USA) and MCF-7/Adr was obtained from The National Cancer Institute (Frederick, MD, USA). Cells were grown and maintained in DMEM, pH 7.4, supplemented with $10 \%(\mathrm{v} / \mathrm{v})$ FBS and $1 \%$ of penicillin/streptomycin stock solution in a humidified, $5 \%(\mathrm{v} / \mathrm{v}) \mathrm{CO}_{2}$ atmosphere at $37^{\circ} \mathrm{C}$.

\subsection{Adherent monolayer cells}

\subsubsection{Cell viability}

Cell viability was assayed with CellTiter Blue® Cell Viability Assay kit (CTB) following the manufacturer's protocol. MDA-MBA-231, MCF-7 and MCF-7/Adr were seeded in 96 -well tissue culture plates at $5 \times 10^{3} /$ well about $24 \mathrm{~h}$ before the treatment. First, we evaluated the effect of a combination of free doxorubicin (1 $\mathrm{uM}$ ) and DHA at varying concentrations (9-562 uM). The aqueous doxorubicin solution and ethanolic DHA (Incromega ${ }^{T M}$ E1050, Croda) solution were freshly prepared before the treatment. Second, we evaluated the cytotoxicity of the encapsulated drug compared to the free drugs with doxorubicin concentrations varying between 0.5-16 uM and DHA between 3.5-112 uM. For both experiments, the cells were incubated with the drugs for $24 \mathrm{~h}$, after that washed thrice with complete DMEM, supplemented with $100 \mathrm{~mL}$, followed by the addition of $20 \mathrm{uL}$ of the CTB reagent. The cells were incubated for $2 \mathrm{~h}$ and the fluorescence intensity 
was measured using a Synergy HT Multi-Mode Microplate Reader with 530/590 ex/em wavelengths.

\subsubsection{Doxorubicin uptake}

The cellular uptake of doxorubicin by the cancer cells was assessed by flow cytometry by using the natural fluorescence of the drug. Cells were seeded in a 12 wells/plate at a density of $1 \times 10^{5}$ cells/well $24 \mathrm{~h}$ before the treatment. The seeding medium was removed and replaced by media containing $16 \mathrm{uM}$ of doxorubicin. After 2 hours incubation, the cells were washed thrice with PBS, trypsinized, centrifuged at $2000 \mathrm{~g}$ for $5 \mathrm{~min}$, suspended in PBS pH 7.4 and analyzed using a BD FACS Calibur flow cytometer. The cells were gated using forward (FSC-H) versus side-scatter (SSC-H) to exclude debris and dead cells before analysis of 10,000 cell counts. The mean fluorescence intensity (MFI) of the cells was measured at $\mathrm{nm}$ the FL-2 channel.

\subsection{Spheroids}

\subsubsection{Preparation of spheroids}

MCF-7/Adr were used to prepare spheroids of $400-500 \mu \mathrm{m}$ diameter, from 10,000 cells in 96 well/plates by a liquid overlay method according to Perche and Torchilin (2012), jcr if you want . Briefly, DMEM with $1.5 \%$ of agarose was preseeded in each well to prevent cell adhesion. After cell seeding, the plates were centrifuged for 15 min at 1,500 RCF. Spheroid formation was monitored using a Nikon Eclipse E400 microscope (Nikon Inc., Melville, USA) at 10×magnification with a Spot Insight ${ }^{\text {TM }}$ 3.2.0 camera with Spot Advanced $^{\mathrm{TM}}$ software (Spot Imaging, Sterling Heights, MI).

\subsubsection{Cytotoxicity}

Cytotoxicity was measured with a Cytotox 96 Non-Radioactive Cytotoxicity kit (Promega; Fitchburg, USA) as reported by Perche and Torchilin (2012). Briefly, both the lactate dehydrogenase $(\mathrm{LDH})$ released in the medium and the LDH from spheroids dissociated by incubation $1 \mathrm{~h}$ at $37^{\circ} \mathrm{C}$ with $0.9 \%$ Triton $\AA-\mathrm{X} 100$ in DMEM media with $10 \%$ FBS were measured. The amount of LDH released into the 
medium after incubation with the treatments was calculated as a percentage in relation to the total (total $\mathrm{LDH}=$ medium $\mathrm{LDH}+$ lysate $\mathrm{LDH}$ ).

\subsubsection{Penetration of doxorubicin in spheroids}

The distribution of free and encapsulated doxorubicin throughout the spheroids was evaluated by confocal microscopy . was evaluated by the degree of penetration of the drug and whether the modification with NLC would improve it. The assessment was-done after $2 \mathrm{~h}$ of incubations with $100 \mu \mathrm{M}$ of doxorubicin in complete DMEM by confocal microscopy using $488 \mathrm{~nm}$ and $535 \mathrm{~nm}$ long pass filter for doxorubicin excitation/emission, respectively. The spheroids were removed from the plate, washed with PBS, placed into Lab-Tek chambers (Fisher Scientific) prior to imaging. They were visualized at 10x magnification, and the distribution of doxorubicin throughout the spheroids was analyzed with a Zeiss LSM 700 confocal microscope using Z-stack imaging with $10 \mu \mathrm{m}$ intervals and the LSM Image Browser software.

\section{Results}

\subsection{NLC characterization}

Table 1 lists the characterization data of the formulations for size, zeta potential, entrapment efficiency and drug loading. The sizes obtained were in the range of 76-86 $\mathrm{nm}$ with values of the polydispersivity index (PDI) lower than 0.22. This suggested that they were monodispersed. The zeta potential was negative for all formulations and varied from -23 to $-36 \mathrm{mV}$. The entrapment efficiency reached about $100 \%$, and the drug loading was $31 \mathrm{mg} / \mathrm{g}$. The others formulations (NLCDHA $0.8 \%$ and NE-DHA 1.5\%) showed very similar results for all of these characteristics (data not shown).

\subsection{Drug release}

The results of the drug release assay performed by dialysis with complete DMEM are included in Figure 1. (is $3 \mathrm{~mL}$ vs $50 \mathrm{~mL}$ sink condition?) The released doxorubicin from NLC-DHA $0.4 \%$ was $5 \pm 1 \%$ in the first $30 \mathrm{~min}$ and increased to $14 \pm 1 \%, 23 \pm 0 \%$ and $30 \pm 1 \%$ at $1 \mathrm{~h}, 2 \mathrm{~h}$ and $4 \mathrm{~h}$, respectively. There was no 
further release for up to $48 \mathrm{~h}$. In contrast, for NLC-DHA $0.8 \%$ and NE-DHA $1.5 \%$, the release at 30 min was $17 \pm 1 \%$ and $17 \pm 2 \%$, respectively and increased to more than $75 \%$ within 4 hours showing higher release of drug than NLC-DHA $0.4 \%$ for all evaluated points. The high release profiles of those two formulations were very similar and showed a lower capacity to retain the drug compared to the formulation with $0.4 \%$ of DHA. The free drug was evaluated as a control and within 2 hours more than $90 \%$ of doxorubicin was measured outside of the bag. Therefore, the formulation that was chosen to the next studies was NLC-DHA $0.4 \%$.

\subsection{NLC stability in serum}

Considering the intended use (intravenous administration), the stability of NLC-DHA $0.4 \%$ in serum was investigated to check for aggregation in presence of proteins. The size, PDI and zeta potential are described in Table 2. Their size was around $70 \mathrm{~nm}$ after incubation with serum for up to $24 \mathrm{~h}$. The variation of PDI was very small (in the range 0.15 to 0.18 ). The differences in zeta potential (-32 to -37 $\mathrm{mV}$ ) were very small and not significant. Thus, the NLC-DHA $0.4 \%$ was very stable after incubation with serum, and the data suggest that this formulation will not aggregate after intravenous administration.

\subsection{In vitro studies}

\subsubsection{Adherent monolayer cells}

\subsubsection{Cytotoxicity of free doxorubicin and DHA}

The cytotoxicity of free doxorubicin and DHA was investigated in three different human cancer cell lines (Figure 2). The concentration of doxorubicin was fixed at $1 \mathrm{UM}$ (why) while the DHA concentration was varied and the DHA was varied. Maybe introduce ratios between the two drugs? The cytotoxicity in MDAMB-231 increased parallel to? was a function of the DHA concentration, with an IC50 for DHA by itself where the IC50 for the isolated fatty acid was between 140 and $280 \mathrm{uM}$. While moderate to now toxicity was detected with $70 \mathrm{uM}$ free DHA (90/5\%), co-treatement with 1 UM DOX significantly decreased cell viability (58\% vs $69 \%$ free dox alone). It was possible to obtain some cytotoxicity at $70 \mathrm{uM}$ and 
the cell viability for isolated doxorubicin and DHA was $69 \pm 2 \%$ and $90 \pm 5 \%$, respectively, while for the association was $58 \pm 3 \%$.

Similarly, in MCF-7 cells ... The second graphic shows the results in MCF-7 and for isolated DHA the IC50 is between 280 and $562 \mathrm{uM}$. The lowest concentration to obtain some enhancement was $140 \mathrm{uM}$ and with it the cell viability was $97 \pm 7 \%, 55 \pm 3 \%$ and $43 \pm 3 \%$ for isolated DHA, doxorubicin and associated drugs, respectively. In the resistant cell line MCF-7/Adr (third graphic) the IC50 for the isolated fatty acid was between 140 and $280 \mathrm{uM}$. It was possible to see some improvement for the association for concentrations as of $280 \mathrm{uM}$, where the cell viability after incubation with isolated DHA, doxorubicin and associated drugs was $38 \pm 7 \%, 73 \pm 1 \%$ and $17 \pm 3 \%$, respectively. Thus, the effect of the association seems to be additive and the most sensitive cell line for the association was the MDA-MB-231, which is an accordance with the previous results of the Bougnoux et al. that found a higher susceptibility for this cell line due to the lipid peroxidation caused by DHA (Mahéo et al, 2005; Vibet et al., 2008). Despite this, all cell lines were sensitive to the drug combination at higher concentrations of DHA.

\subsubsection{Cytotoxicity of the NLC}

The cytotoxicity of the NLC was evaluated in monolayer culture for the cell lines MDA-MB-231, MCF-7 and MCF-7/Adr using Cell-Titer Blue (Figure 3). For MDA-MB-231 (Figure $3 \mathrm{~A}$ ) at $2 \mathrm{uM}$ of doxorubicin (equivalent to $14 \mathrm{uM}$ of DHA when associated) the cell viability for cells incubated with free doxorubicin and free doxorubicin+DHA was $49 \pm 5 \%$ and $44 \pm 4 \%$, while for NLC and NLC-DHA it was $38 \pm 1 \%$ and $32 \pm 2 \%$, respectively. The benefit of drug association was apparent from this ratio $\mathrm{xx}$. This is the concentration at which it was possible starting to see some benefits for the NLC-DHA $0.4 \%$. With the highest evaluated concentrations of drugs ( $16 \mathrm{uM}$ of doxorubicin and $112 \mathrm{uM}$ of DHA), the cell viability was $21 \pm 0 \%$, $20 \pm 0 \%, 17 \pm 1 \%, 9 \pm 2 \%$ for free doxorubicin, free doxorubicin+DHA, NLC and NLC-DHA, respectively. It is noteworthy that for all of the concentrations from $2 \mathrm{uM}$ of doxorubicin, the formulation with the associated drugs had a more cytotoxic effect compared to the encapsulated non-associated doxorubicin or free drugs. 
For the sensitive MCF-7 (Figure $3 \mathrm{~B}$ ), with $2 \mathrm{uM}$ of doxorubicin the cell viability was $39 \pm 8 \%, 37 \pm 8 \%, 31 \pm 1 \%, 31 \pm 1 \%$ and at 16 uM it was $18 \pm 1 \%, 17$ $\pm 2 \%, 14 \pm 0 \%, 12 \pm 0 \%$ for free doxorubicin, free doxorubicin+DHA, NLC and NLC-DHA, respectively. Thus, the cytotoxicity for all the evaluated concentrations was very similar for all the treatments.

The cell viability for resistant MCF-7/Adr is described in the Figure $3 \mathrm{C}$. Higher anticancer activity of NLC-based drug combination over co-treatment with both free drugs was evidenced from $4 \mathrm{uM}$ dox to $16 \mathrm{uM}$ dox. At $4 \mathrm{uM}$, ..It was possible to see some improvement due to the association and encapsulation from $4 \mathrm{uM}$ of doxorubicin ( $28 \mathrm{uM}$ of DHA) where the cell viability was $62 \pm 8 \%, 63 \pm 2 \%$, $37 \pm 2 \%, 30 \pm 1 \%$ for free doxorubicin, free doxorubicin+DHA, NLC and NLC-DHA, respectively. The highest cytotoxicity was detected at 16uM with xx For the others higher concentrations the activity of the formulations were still better and the best result was found at $16 \mathrm{uM}$ of doxorubicin (112 uM of DHA) with $59 \pm 2 \%, 61 \pm 5 \%$, $20 \pm 1 \%, 7 \pm 0 \%$ of viability for free doxorubicin, free doxorubicin+DHA, NLC and NLC-DHA, respectively. There was no significant difference between free doxorubicin and free doxorubicin+DHA that might be due to the low concentration of the fatty acid. In addition, the Blank NLC did not show any significant cytotoxicity for all the evaluated cell lines.

To confirm these results we have also evaluated the cytotoxicity in monolayer cultures with MCF-7/Adr using the LDH assay (CytoTox 96®) and the results were in agreement with Cell titer blue the same verified by Cell-Titer Blue® (data not shown).

\subsubsection{Doxorubicin uptake}

Doxorubicin uptake was evaluated by FACS? The evaluation of doxorubicin uptake performed by FACS for the three cell lines are described in Figure 4. The drug sensitive cell lines MDA-MB-231 and MCF-7 had the same profile of drug uptake and similar fluorescence intensities for the cells incubated with free doxorubicin, free doxorubicin+DHA, NLC and NLC-DHA. In contrast, for the resistant cell line MCF-7/Adr, we observed a 2.6-fold higher .. the fluorescence of the cells incubated with the formulations were 2.6 folds higher than the cells incubated with the free drugs. There was no difference between free doxorubicin 
and free doxorubicin+DHA or NLC and NLC-DHA. Note that no cell-associated fluorescence was detected with the blank formulation. The blank formulation did not result in fluorescent cells.

\subsubsection{Spheroids}

\subsubsection{Cytotoxicity}

The cytotoxicity of the formulations and free drugs in spheroids was assessed using CytoTox 96® Non-Radioactive Cytotoxicity Assay (Figure 5). The graphic the treatment of the spheroids with NLC-DHA (concentrations) resulted in a $93 \pm 6 \%$ LDH release. For NLC, Lipodox, free doxorubicin+DHA and free doxorubicin the release was $51 \pm 13 \%, 44 \pm 5 \%, 35 \pm 10 \%$ and $25 \pm 9 \%$, respectively. In addition, we visualized through microscope after $24 \mathrm{~h}$ of incubation with the treatments formulations a complete destruction of the spheroid, with many scattered loose cells (data not shown) (you can cite someones maybe). It is noteworthy that The blank formulation and the cells treated only with media (control) showed no significant toxicity (less than $2 \% \mathrm{LDH}$ release and no alteration of the spheroid structure).

\subsubsection{Doxorubicin penetration}

To evaluate the potential of the formulations for penetration of avascular tumors the spheroids, we analyzed the distribution of doxorubicin throughout the tumor spheroids by confocal microscopy (Figure 7). From left to the right, images which represent deeper layers, a reduction of the fluorescence occurred for all the treatments. Differences in the fluorescence intensities between the groups can be organized for all analyzed layers as follows: NLC-DHA $0.4 \%>$ NLC $0.4 \%>$ Lipodox $\AA>$ Free doxorubicin+DHA = Free doxorubicin. Furthermore, as example, at $70 \mathrm{uM}$ depth (deepest layer), the spheroids incubated with NLC-DHA $0.4 \%$ is notably more fluorescent in the inner core of the sectional cut than the others groups, also showing more penetration for this formulation. The spheroids incubated with the Blank NLC as well as the control group (only media) showed no fluorescence (data not shown). Here you should give numbers, choose the 70uM 
section and check intensity using ImageJ then add this info to the figure and in the text.

\subsection{Discussion}

Many efforts have been made to improve cancer treatment with combination therapy (Jassem et al, 2001; Storniolo et al, 2008; Livi et al, 2009; Keith et al, 2012), and studies have described the increase of the doxorubicin activity through the association with DHA (Germain et al, 1998; Hardman et al., 2001; Mahéo, 2005; Colas et al, 2006; Bougnoux et al, 2009; Siddiqui et al, 2011; Hajjaji et al, 2012). However, problems related to the route, formulations and schedule still need have still to be addressed and nanocarries have been proposed as a tool to overcome these limitations (Storniolo et al, 2008). Recently, NLC has been described as a promising drug delivery system for enhanced cancer therapy (Zhang et al, 2008; Joshi et al, 2009; Yang et al, 2012). Among the advantages of the NLC is the retention of the drug in the lipid core to promote the control of release. However, works have recommended incorporation of up to $30 \%$ of liquid of the total lipid (Radtke et al, 2001; Müller et al, 2002). We hypothesized that a NLC loaded with doxorubicin and DHA triglyceride could enhance the antitumor effect. A NLC was developed by loading doxorubicin and DHA at $0.4 \% \mathrm{w} / \mathrm{v}$ (corresponding to $30 \%$ liquid lipid) and evaluated for its release profile in comparison with formulations containing higher DHA concentrations. Our data (Figure 1) clearly showed a controlled doxorubicin release for NLC-DHA $0.4 \%$ whereas the NLC-DHA 0.8\% (50\% liquid lipid) and NE-DHA 1.5\% (100\% liquid lipid) were unable to retain the drug in the matrices. Despite that, a fast drug release (burst effect) of $30 \%$ was verified for NLC-DHA $0.4 \%$. Similar burst effect has been described for SLN and NLC in many works as a characteristic of these formulations (Radtke et al, 2001; Müller et al., 2002). We speculate that this caveat? effort may be related to some significant part of the formed ionic pair that is located in the interface of the nanoparticle (as represented in the scheme of Figure 7), and would be quickly released by diffusion after incubation with media. This could be related to the manufacturing process (hot homogenization) that favors the accumulation of the drug in the outer shell of the lipid core (Müller et al., 2002), or also-due to hydroxyl groups of doxorubicin and carboxyl group of the 
oleic acid that confer some amphiphilic character for the ionic pair. Nevertheless, we further speculate that this amount of fast drug release could have a priming effect while the $70 \%$ remaining not released up to $48 \mathrm{~h}$ could have the potential to modify the pharmacokinetics, prolonging the circulation and target the tumor by EPR effect. In addition, to further enrich the targeting issue, it is noteworthy our previous work (Mussi et al, 2013) proposed the ionic pair strategy that resulted in higher release ( $>80 \% \mathrm{c}$ in the first hour) of the drug in low $\mathrm{pH}$, which might be interesting to tumor site-specific release of doxorubicin. Thus, the formulation NLCDHA $0.4 \%$ which presented interesting physicochemical properties and compatible for intravenous administration was elected for further experiments.

The next step was the in vitro evaluation of activity in cell monolayer model with free drugs and the developed formulation in sensitive and resistant breast cancer cell lines. Firstly, we evaluated the cytotoxicity of the free drugs combination and the lowest molar ratio to obtain some improvement was 1:70 of doxorubicin/DHA in MDA-MB-231. (need to introduce ratios before) Secondly, we evaluated the activity of NLC-DHA $0.4 \%$ compared with free drugs and NLC (formulation containing only doxorubicin). Although, the ratio of doxorubicin/DHA in the NLC-DHA was 10-fold lower (1:7) than the lowest additive ratio for free drugs? that observed for the improvement of free drugs, the combination showed advantages due to the encapsulation. This was observed in MDA-MB-231 and MCF-7/Adr but not in MCF-7, where higher concentrations of DHA could be necessary. However, the increase of DHA was not possible in this model because concentrations higher than $112 \mathrm{uM}$ would imply using $16 \mathrm{uM}$ dox implies, consequently, the increase of doxorubicin concentration (>16 uM) that would reach $0 \%$ of cell viability.

Regarding the results in MCF-7/Adr cells, the advantages of NLC-borne DHA and dox co-delivery were apparent and could be attributed to DHA since uptake of NLC and NCL-DHA were similar benefits of the associated drugs when encapsulated was notably observed and it was due to the activity of DHA, once the doxorubicin uptake verified for both NLC-DHA and NLC were equivalents. Beside this, NCL and NLC-DHA showed meaningly higher activity compared to the free drugs. This system seems to be able to bypass P-glycoprotein efflux pump since 
we verified its overexpression in this cell line (data not shown) and increased dox uptake over free drug the higher doxorubicin uptake for the formulations was verified/observed?. Thus, the encapsulation of doxorubicin is promising to reverse the resistance in cancer cell line monolayer model and the combination with DHA proved to be interesting to further enhance the activity.

The last part of the work was the evaluation of activity in spheroids. They have been described as a more relevant in vitro tumor model for use in assessment of drug combinations (Perche and Torchilin, 2012) since they mimic in vivo tumors in many ways, including gradients of $\mathrm{pH}, \mathrm{PO}_{2}$ and vascularization (Hirschhaeuser et al, 2010)(Swati Cancer letters). Due to these characteristics, this model is more relevant suitable for drug penetration studies in vitro in comparison to monolayered cells (Dufau et al, 2012). In addition, spheroids have been used as a tool for negative selection to evaluate drug candidates and most therapeutic approaches were found to be less active in this model than cell monolayer cultures (Hirschhaeuser et al, 2010). The high activity of NLC-DHA 0.4\% in MCF-7/Adr was verified for both monolayer and spheroid models, showing cytotoxicity close to $100 \%$. However, the NLC $0.4 \%$ was less cytotoxic in spheroids than in monolayer model confirming the expectation aforementioned. Cytotoxicity in spheroids was confirmed using These results were also confirmed in spheroids using a different viability assay (CellTiter-Gloß Luminescent Cell Viability Assay; Promega) that evaluates the viable cells based on quantitation of the cellular ATP present (data not shown/supplemental info?). The importance of drug encapsulation was clear since the NLC $0.4 \%$ was more cytotoxic than free doxorubicin and NLC-DHA $0.4 \%$ was more cytotoxic than free doxorubicin + DHA. The combination of doxorubicin and DHA also enhanced the activity verified by the higher cytotoxicity of free doxorubicin + DHA than free doxorubicin and greater cytotoxicity for NLC-DHA $0.4 \%$ than NLC 0.4\%. Another benefit for NLC-DHA $0.4 \%$ was the greater penetration in spheroid structure that overcame the binding site barrier where the DHA played some rule. The presence of this barrier, characterized by a limited drug penetration in tumor structure, was confirmed since free doxorubicin was confined to the periphery of the spheroid as previously reported (Perche and Torchilin, 2012 actually JCR since no confocal in CBT?)(Kim biomaterials) and in 
tumor in patients (Lankelma et al., 1999). We also verified an expressively greater penetration and cytotoxicity in spheroids for NLC-DHA $0.4 \%$ than a commercial liposomal formulation (Lipodox®). These results strengthen the importance of combination of doxorubicin and DHA as well as their co-encapsulation in NLC.

Altogether, NLC-DHA is a promising formulation with increased anticancer activity over free drugs against three cancer cell lines and in a spheroid model.Taking all together, the NLC-DHA has shown to be promising in terms of the formulation characteristics and its activity that was evidently high in an aggressive cancer cell line MDA-MB-231 and the drug resistant MCF-7/Adr compared to the two commercially available forms of doxorubicin (free hydrochloride salt and liposomal). Thus, we propose this newly developed nanocarrier codelivering doxorubicin and DHA to have the potential for effective combination cancer therapy. that have a potential for treatment of drug sensitive and resistant cell lines to qualify as a truly multidrug delivery nanomedicine for cancer therapy.

\subsection{Conclusion}

Our newly developed nanostructured lipid carrier (NLC) loaded with doxorubicin and DHA shown size, zeta potential and serum stability adequate for parental administration and a controlled release. The in vitro antitumor activity of such NLC loaded with doxorubicin and DHA $0.4 \%$ in monolayer models was the same as the free drugs for the sensitive MCF-7, slightly higher for MDA-MB-231 and significant for MCF-7/Adr compared to the free drugs and the entrapped drug not associated with DHA. Thus, the association of doxorubicin and DHA as well as their co-encapsulation in NLC improved the antitumor activity in these aggressive tumor types and may overcome drug resistance associated with P-glycoprotein activity. These findings with cell monolayer were supported spheroids that showed an enhanced penetration into the tumor structure. Finally, the NLC loaded with doxorubicin and DHA represents a promising alternative combination cancer therapy.

\section{References}


Bougnoux, P., Hajjaji, N., Ferrasson, M.N., Giraudeau, B., Couet, C., Le Floch, O., 2009. Improving outcome of chemotherapy of metastatic breast cancer by docosahexaenoic acid: a phase II trial. Br J Cancer. 101, 78-85.

Colas, S., Mahéo, K., Denis, F., Goupille, C., Hoinard, C., Champeroux, P., Tranquart, F., Bougnoux, P. Sensitization by dietary docosahexaenoic acid of rat mammary carcinoma to anthracycline: a role for tumor vascularization. Clin Cancer Res. 12, 5879-5886, 2006.

Dufau I, Frongia C, Sicard F, Dedieu L, Cordelier P, et al. Multicellular tumor spheroid model to evaluate spatio-temporal dynamics effect of chemotherapeutics: application to the gemcitabine/CHK1 inhibitor combination in pancreatic cancer. BMC Cancer 12: 15. 2012

Franziska Hirschhaeuser, Heike Menne, Claudia Dittfeld, Jonathan West, Wolfgang Mueller-Klieser, Leoni A. Kunz-Schughart. Multicellular tumor spheroids: An underestimated tool is catching up again. Journal of Biotechnology 148 (2010) 3-15.

Germain, E., Chajès, V., Cognault, S., Lhuillery, C., Bougnoux, P., 1998. Enhancement of doxorubicin cytotoxicity by polyunsaturated fatty acids in the human breast tumor cell line MDA-MB-231: relationship to lipid peroxidation. Int J Cancer. 75, 578-583.

Hajjaji N, Besson P, Bougnoux P. Tumor and non-tumor tissues differential oxidative stress response to supplemental DHA and chemotherapy inrats. Cancer Chemother Pharmacol. 2012 Jul; 70 (1):17-23.

Hardman, W.E., Avula, C.P., Fernandes, G., Cameron, I.L., 2001. Three percent dietary fish oil concentrate increased efficacy of doxorubicin against MDA-MB 231 breast cancer xenografts. Clin Cancer Res. 7, 2041-2049.

Hirschhaeuser F, Menne H, Dittfeld C, West J, Mueller-Klieser W, KunzSchughart LA. Multicellular tumor spheroids: an underestimated tool is catching up again. J Biotechnol. Jul 1;148(1):3-15. 2010.

Howes, A.L., Chian, G.G., Lang, E.S., Ho C.B., Powis G., Vuori K., Abraham R.T., The phosphatidylinositol 3-kinase inhibitor, PX-866, is a potent inhibitor of cancer cell motility and growth in three-dimensional cultures. Mol Cancer Ther. 2007 Sep;6(9):2505-14. Epub 2007 Aug 31.

Jassem J, Pieńkowski T, Płuzańska A, Jelic S, Gorbunova V, Mrsic-Krmpotic Z, Berzins J, Nagykalnai T, Wigler N, Renard J, Munier S, Weil C; Central \& Eastern Europe and Israel Pacitaxel Breast Cancer Study Group. Doxorubicin and paclitaxel versus fluorouracil, doxorubicin, and cyclophosphamide as firstline therapy for women with metastatic breast cancer: final results of a randomized phase III multicenter trial, Journal of Clinical Oncology, vol. 19, no. 6, pp. 1707-1715, 2001. 
Joshi, M D, Müller R.H. Lipid nanoparticles for parenteral delivery of actives. European Journal of Pharmaceutics and Biopharmaceutics 71, 161-172, 2009.

Keith T. Flaherty, Jeffery R. Infante, Adil Daud, Rene Gonzalez, Richard F. Kefford, Jeffrey Sosman, Omid Hamid, Lynn Schuchter, Jonathan Cebon, Nageatte Ibrahim, Ragini Kudchadkar, Howard A. Burris, III, Gerald Falchook, M., Alain Algazi, Karl Lewis, Georgina V. Long, Igor Puzanov, Peter Lebowitz, Ajay Singh, Shonda Little, Peng Sun, Alicia Allred, Daniele Ouellet, Kevin B. Kim, Kiran Patel and Jeffrey Weber. Combined BRAF and MEK Inhibition in Melanoma with BRAF V600 Mutations. N Engl J Med 2012; 367:1694-1703, November 1, 2012.

Li, Y., Wang, J., Wientjes, M.G., Au, J.L., 2012. Delivery of nanomedicines to extracellular and intracellular compartments of a solid tumor. Adv Drug Deliv Rev. 64, 29-39.

Livi L, Meattini I, Cardillo Cde L, Mangoni M, Greto D, Petrucci A, Rampini A, Bruni A, Galardi A, Cataliotti L, Biti G. Non-pegylated liposomal doxorubicin in combination with cyclophosphamide or docetaxel as first-line therapy inmetastatic breast cancer: a retrospective analysis. Tumori, vol. 95, no. 4, pp. 422-426, 2009.

Maeda, H., Wu, J., Sawa, T., Matsumura, Y., Hori, K., Tumor vascular permeability and the EPR effect in macromolecular therapeutics: a review, J. Control. Release 65 (2000) 271-284.

Mahéo, K., Vibet, S., Steghens, J.P., Dartigeas, C., Lehman, M., Bougnoux, P., Goré, J., 2005. Differential sensitization of cancer cells to doxorubicin by DHA: a role for lipoperoxidation. Free Radic Biol Med. 39, 742-751

Mehnert, W., Mäder, K., 2001. Solid lipid nanoparticles: production, characterization and applications. Adv Drug Deliv Rev. 47, 165-196.

Müller, R.H, Radtke, M, Wissing, S.A. Nanostructured lipid matrices for improved microencapsulation of drugs. International Journal of Pharmaceutics. Volume 242, Issues 1-2, 21 August, Pages 121-128, 2002

Mussi SV, Silva RC, Oliveira MC, Lucci CM, Azevedo RB, Ferreira LA. New approach to improve encapsulation and antitumor activity of doxorubicin loaded in solid lipid nanoparticles. Eur J Pharm Sci. 2013 Jan 23; 48(1-2):282-90.

Okuda, T. \& Kidoaki, S. Multidrug Delivery Systems with Single Formulation Current status and Future Perspective Journal of Biomaterials and Nanobiotechnology, 2012, 3, 50-60.

Perche, F., Torchilin, V.P., Cancer cell spheroids as a model to evaluate chemotherapy protocols, Cancer Biol. Ther. 13; 2012. 
Primeau, A.J., Rendon, A., Hedley, D., Lilge, L., Tannock, I.F., 2005. The distribution of the anticancer drug doxorubicin in relation to blood vessels in solid tumors. Clin Cancer Res. 11, 8782-8788.

Radtke, M., Müller, R.H. NLC-nanostructured lipid carriers: the new generation of lipid drug carriers, New Drugs 2, 48-52. 2001

Serpe, L., Satalano, M.G., Cavalli, R., Ugazio, E., Bosco, O., Canaparo, R., Muntoni, E., Frairia, R., Gasco, M.R., Eandi, M., Zara, G.P., 2004. Cytotoxicity of anticancer drugs incorporated in solid lipid nanoparticles on HT-29 colorectal cancer cell line. Eur J Pharm Biopharm. 58, 673-680.

Shi Y, Moon M, Dawood S, McManus B, Liu PP. Mechanisms and management of doxorubicin cardiotoxicity. Herz. 2011 Jun; 36(4):296-305.

Siddiqui, R.A., Harvey, K.A., Xu, Z., Bammerlin, E.M., Walker, C., Altenburg, J.D., 2011. Docosahexaenoic acid: a natural powerful adjuvant that improves efficacy for anticancer treatment with no adverse effects. Biofactors. 37, 399412.

Souto, E.B., R.H. Müller, Lipid nanoparticles: effect on bioavailability and pharmacokinetic changes, Handb. Exp. Pharmacol. 197, 115-141. 2010.

Storniolo, A. M., Pegram, M. D., Overmoyer, B. et al., Phase I dose escalation and pharmacokinetic study of lapatinib in combination with trastuzumab in patients with advanced ErbB2-positive breast cancer. Journal of Clinical Oncology, vol. 26, no. 20, pp. 3317-3323, 2008.

Torchilin, V. Tumor delivery of macromolecular drugs based on the EPR effect. Adv Drug Deliv Rev. 63, 131-135. 2011.

Trédan, O., Galmarini, C.M., Patel, K., Tannock, I.F. Drug resistance and the solid tumor microenvironment. J Natl Cancer Inst. 99, 1441-1454. 2007.

Vibet, S., Goupille, C., Bougnoux, P., Steghens, J.P., Goré, J., Mahéo, K.Sensitization by docosahexaenoic acid (DHA) of breast cancer cells to anthracyclines through loss of glutathione peroxidase (GPx1) response. Free Radical Biology \& Medicine 44, 1483-149, 2008.

Wissing, S.A., Kayser, O.; Müller, R.H.Solid lipid nanoparticles for parenteral drug delivery. Adv Drug Deliv Rev. 56, 1257-1272, 2004.

Wong, H.L., Rauth, A.M., Bendayan, R., Manias, J.L., Ramaswamy, M., Liu, Z., Erhan, S.Z., Wu, X.Y., 2006. A new polymer-lipid hybrid nanoparticle system increases cytotoxicity of doxorubicin against multidrug-resistant human breast cancer cells. Pharm Res. 23, 1574-1585. 
Yang XY, Li YX, Li M, Zhang L, Feng LX, Zhang N. Hyaluronic acid-coated nanostructured lipid carriers for targeting paclitaxel to cancer. Cancer Lett. Jul 7. 2012

Zhang, X.-g., Miao J., Dai, Y.-Q., Du, Y.-Z., Yuan, H., Hu, F.-Q., Reversal activity of nanostructured lipid carriers loading cytotoxic drug in multi-drug resistant cancer cells, Int. J. Pharm 361 (2008) 239-244. 


\section{Tables}

Table 1. Nanostructured lipid carrier (NLC) formulations characterization

\begin{tabular}{|c|c|c|c|}
\hline \multicolumn{2}{|c|}{ Formulation } & $\begin{array}{l}\text { Size } \\
(\mathrm{nm})\end{array}$ & PDI \\
\hline \multicolumn{2}{|c|}{ Blank NLC } & $84 \pm 1$ & $0.22 \pm 0.03$ \\
\hline \multicolumn{2}{|c|}{ NLC $0.4 \%$} & $76 \pm 0$ & $0.20 \pm 0.01$ \\
\hline \multicolumn{2}{|c|}{ NLC-DHA 0.4\% } & $86 \pm 7$ & $0.13 \pm 0.04$ \\
\hline \multirow{2}{*}{\multicolumn{4}{|c|}{$\begin{array}{l}\mathrm{N}=3 ; \text { Averages } \pm \text { SD; PDI = Polydispersity index; } \\
\text { Table 2. NLC-DHA } 0.4 \% \text { stability in serum }\end{array}$}} \\
\hline & & & \\
\hline $\begin{array}{c}\text { Time } \\
\text { (h) }\end{array}$ & $\begin{array}{l}\text { Size } \\
(\mathrm{nm})\end{array}$ & PDI & $\begin{array}{l}\text { Zeta } \\
\text { potential } \\
(\mathrm{mV})\end{array}$ \\
\hline 0 & $68 \pm 1$ & $0.16 \pm 0.01$ & $-34 \pm 1$ \\
\hline 4 & $70 \pm 0$ & $0.18 \pm 0.01$ & $-32 \pm 1$ \\
\hline 8 & $70 \pm 0$ & $0.15 \pm 0.00$ & $-34 \pm 1$ \\
\hline 24 & $70 \pm 1$ & $0.16 \pm 0.01$ & $-37 \pm 2$ \\
\hline
\end{tabular}

\begin{tabular}{lll}
$\begin{array}{l}\text { Zeta } \\
\text { potential } \\
(\mathrm{mV})\end{array}$ & $\begin{array}{l}\text { EE } \\
\text { Doxorubicin } \\
(\%)\end{array}$ & $\begin{array}{l}\text { DL } \\
\text { Doxorubicin/ } \\
\text { NLC lipids } \\
(\mathrm{mg} / \mathrm{g})\end{array}$ \\
\hline
\end{tabular}


Figures

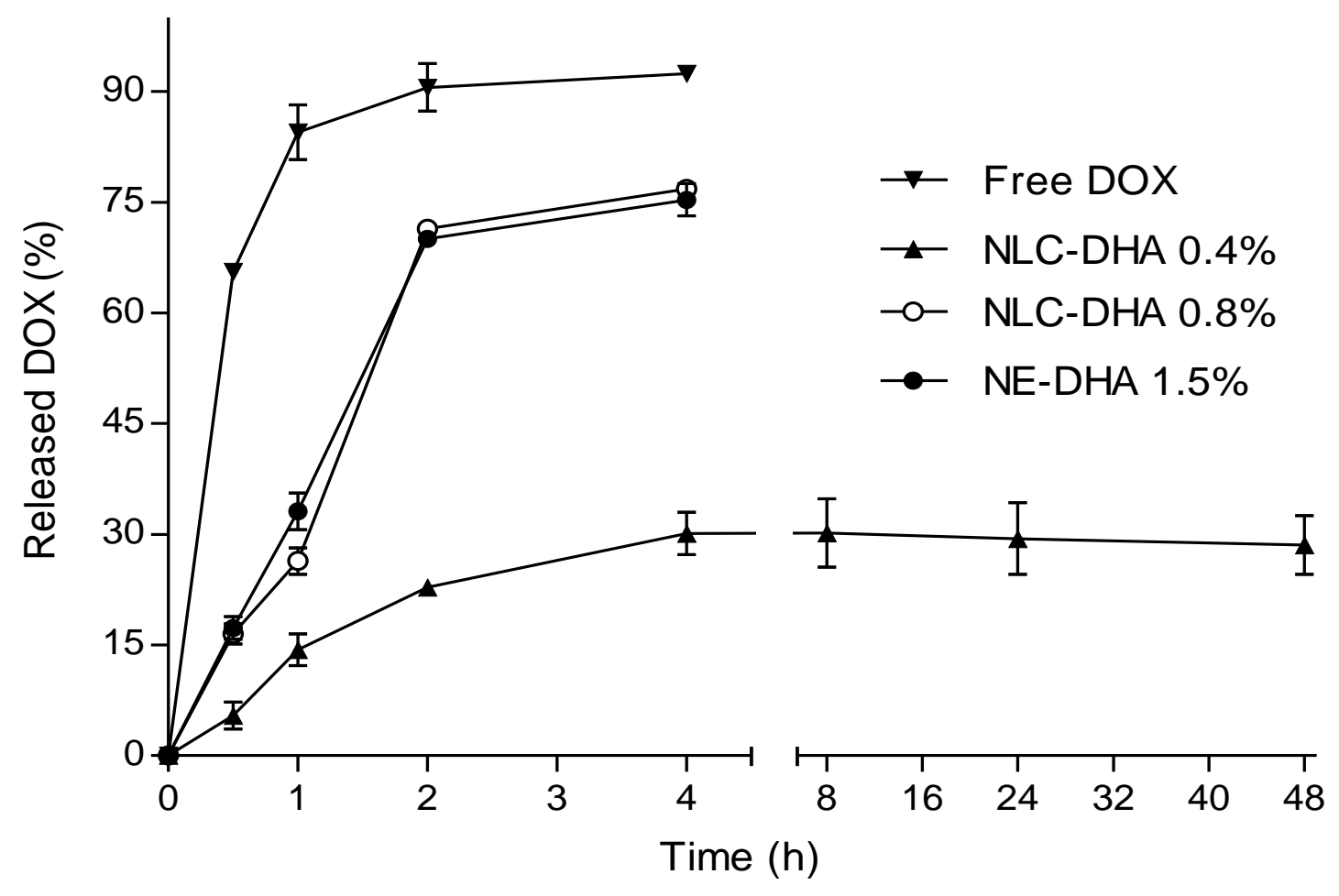

Figure 1. Doxorubicin release in complete DMEM by dialysis using a cellulose ester membrane $100 \mathrm{KDa}$. Formulations loaded doxorubicin or free doxorubicin were diluted in media and placed into dialysis tubes, incubated in $50 \mathrm{ml}$ of media for up to $48 \mathrm{~h}$ at $37^{\circ} \mathrm{C}$, with continuous shaking at $250 \mathrm{RPM}$. The released doxorubicin measured in the media was analyzed by fluorescence. $\mathrm{N}=3$; Averages $\pm \mathrm{SD}$; 
(A) MDA-MB-231

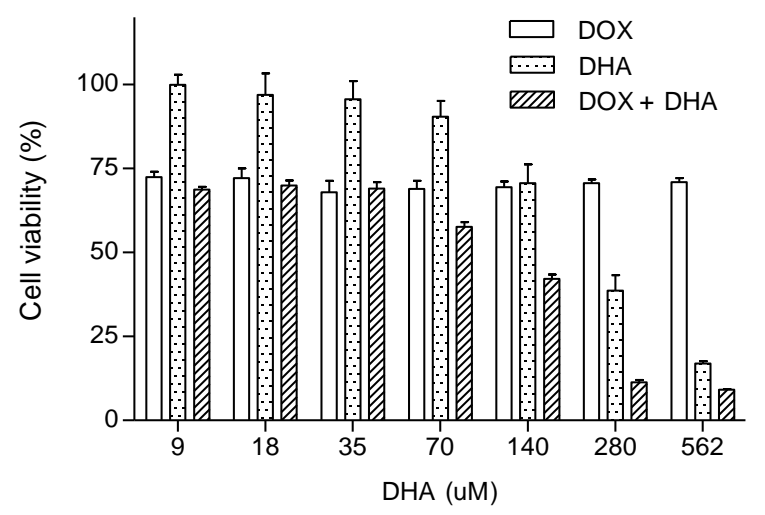

(B) MCF-7

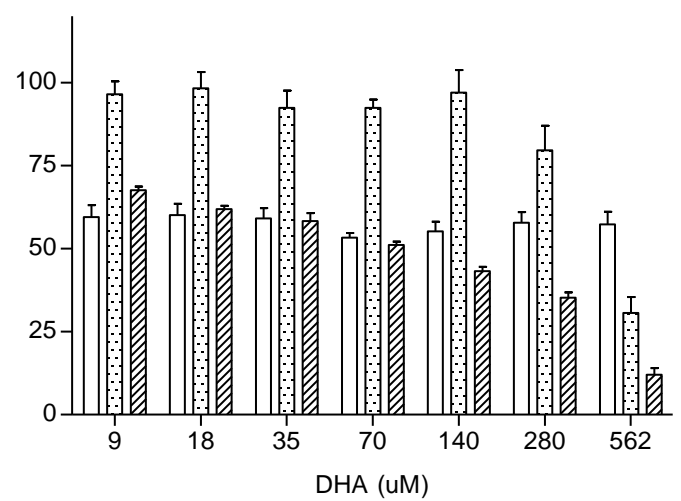

(C) MCF-7/Adr

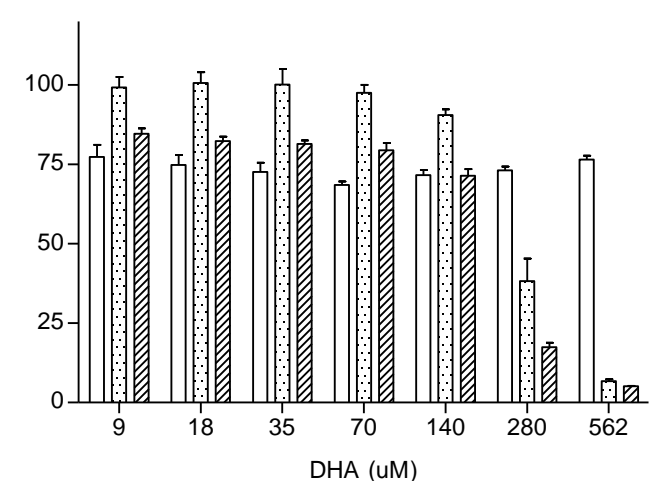

Figure 2. Cytotoxicity of free doxorubicin (DOX), free DHA (DHA) and free doxorubicin + DHA (DOX+DHA) evaluated in MCF-7 and MCF-7/Adr after $24 \mathrm{~h}$ of incubation with $1 \mathrm{uM}$ of doxorubicin and 9 to $562 \mathrm{uM} \mathrm{DHA.} \mathrm{N}=3$; Averages \pm SD 
(A) MDA-MB-231

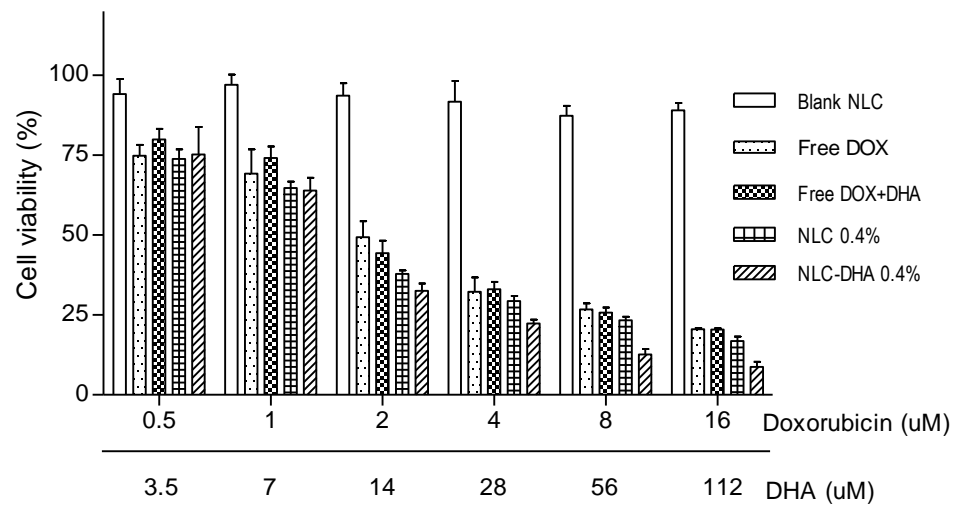

(B) MCF-7

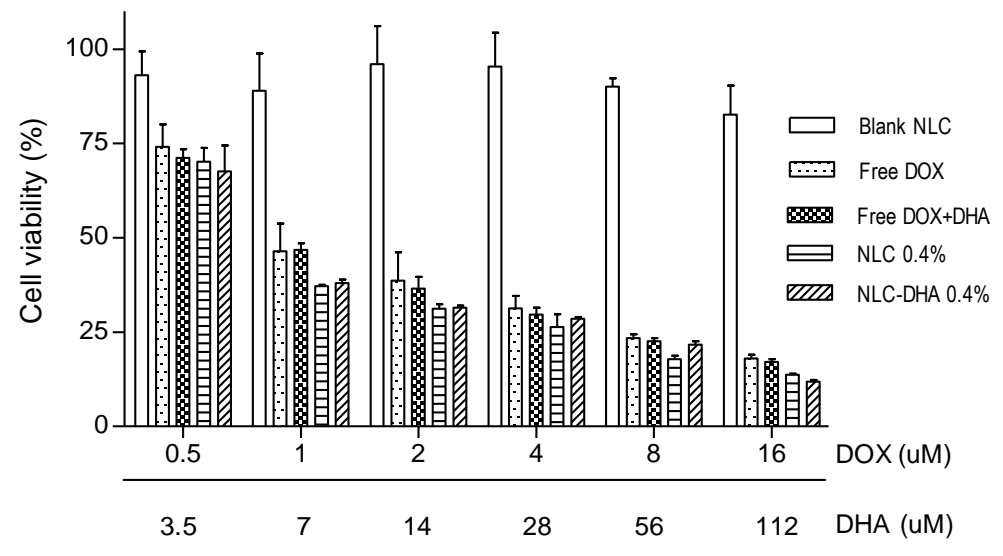

(C) MCF-7/Adr

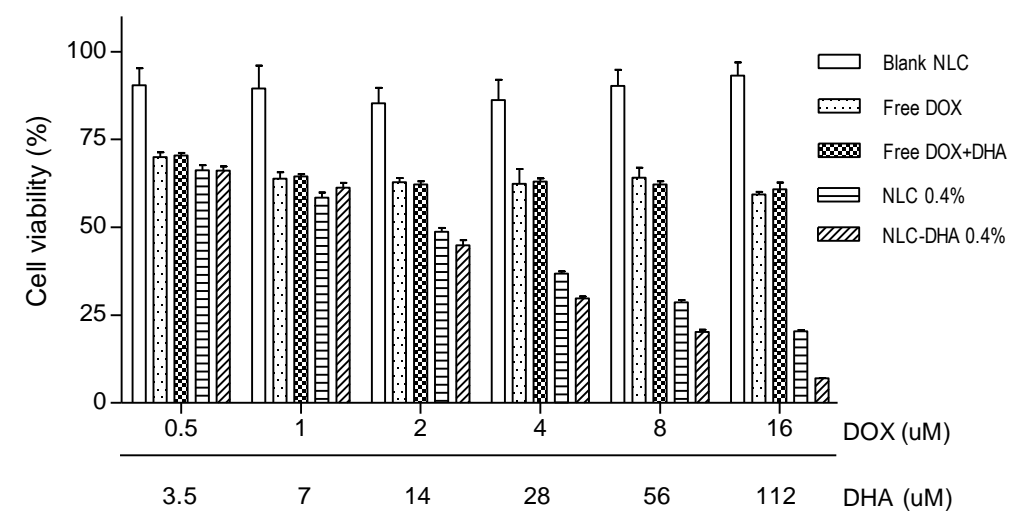

Figure 3. Cytotoxicity of blank formulation (Blank NLC), free doxorubicin (Free DOX), free doxorubicin + DHA (Free DOX+DHA), doxorubicin-loaded NLC (NLC $0.4 \%$ ) and doxorubicin + DHA-loaded NLC (NLC-DHA 0.4\%) evaluated in (A) MDA-MB-231, (B) MCF-7, (C) MCF-7/Adr after $24 \mathrm{~h}$ of incubation. $\mathrm{N}=3$; Averages \pm SD. 


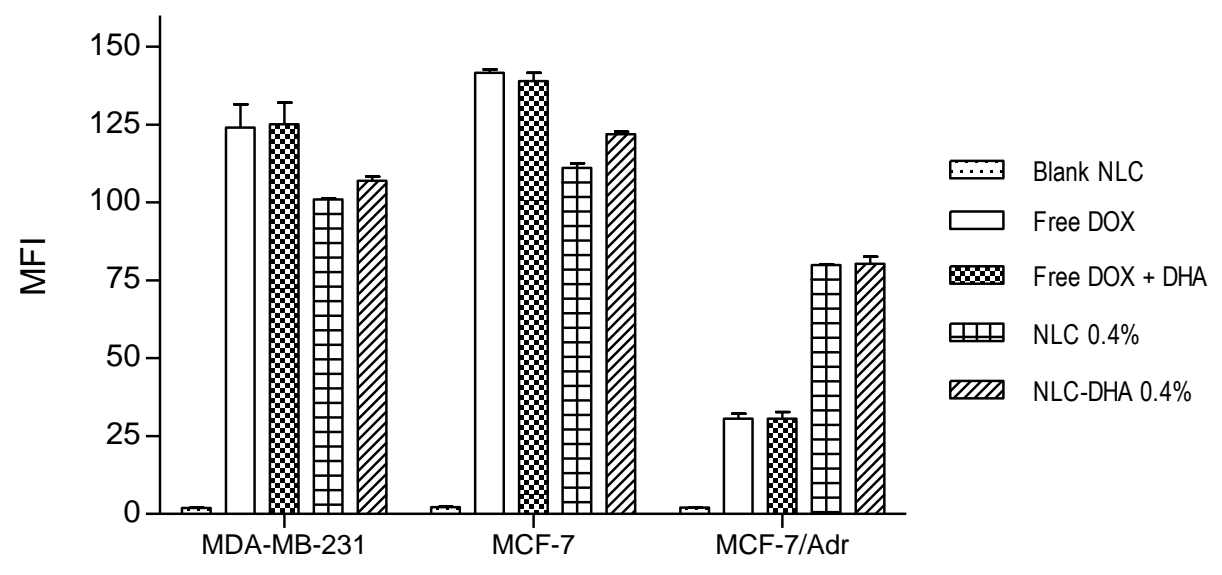

Figure 4. Uptake of blank formulation (Blank NLC), free doxorubicin (Free DOX), free doxorubicin + DHA (Free DOX+DHA), doxorubicin-loaded NLC (NLC 0.4\%) and doxorubicin + DHA-loaded NLC (NLC-DHA 0.4\%) for-in the three human cancer cell lines after 1 hour of incubation with the equivalent of $16 \mathrm{uM}$ of doxorubicin and analyzed for mean fluorescence intensity (MFI) by FACS. $\mathrm{N}=3$; Averages \pm SD. 


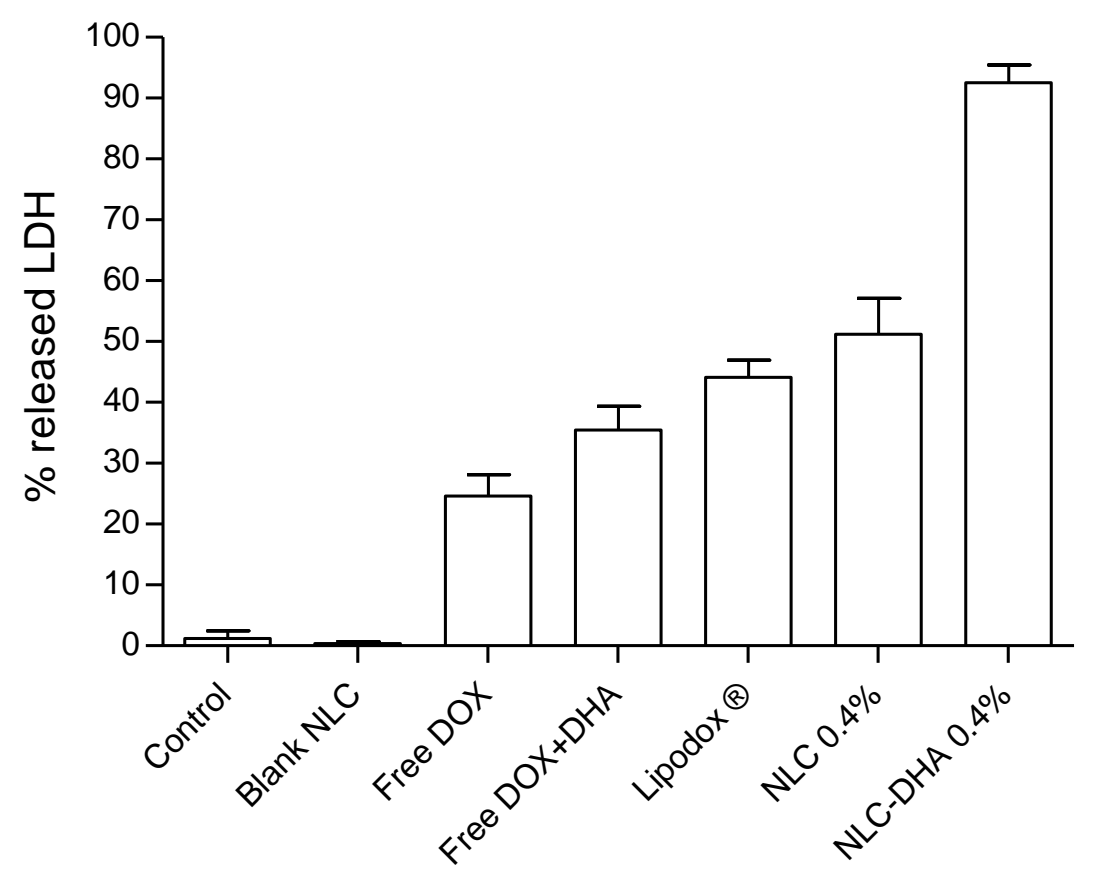

Figure 5. Toxicity of blank formulation (Blank NLC), free doxorubicin (Free DOX), free doxorubicin + DHA (Free DOX+DHA), liposomal doxorubicin (Lipodox®), doxorubicin-loaded NLC (NLC 0.4\%) and doxorubicin + DHA-loaded NLC (NLCDHA $0.4 \%$ ) in against MCF-7/Adr spheroids. The incubation was $48 \mathrm{~h}$ with the equivalent of $100 \mu \mathrm{M}$ of doxorubicin. $\mathrm{N}=3$; Average \pm SD. 


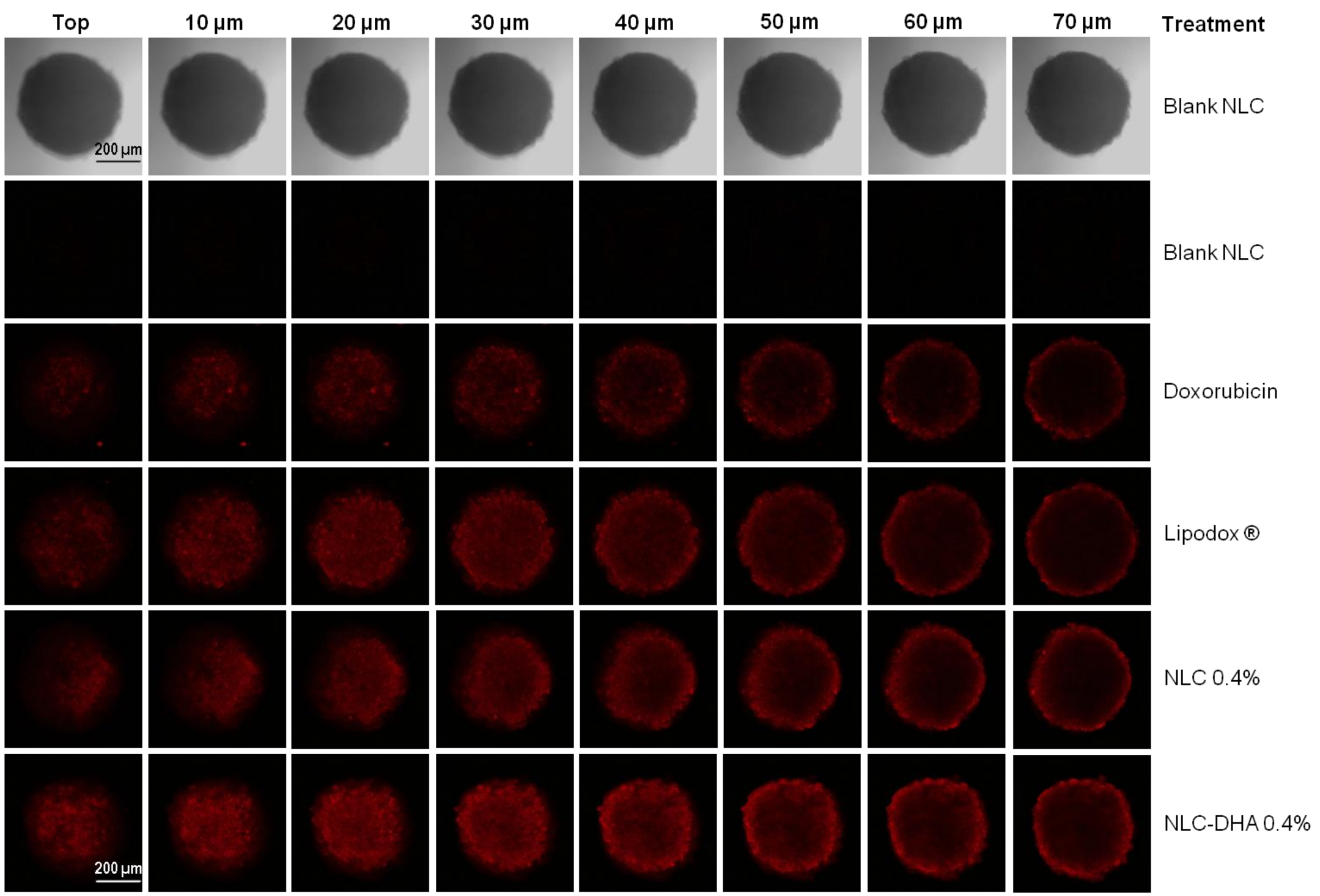

Figure 6 - Confocal images of MCF-7/Adr tumor spheroids after incubation for 2 hours with different treatments. Z-stack images were obtained from the top towards the tumor spheroid equatorial plane in 10 um intervals thickness. The images are representative of triplicate (duplicate?) analysis /samples?. 


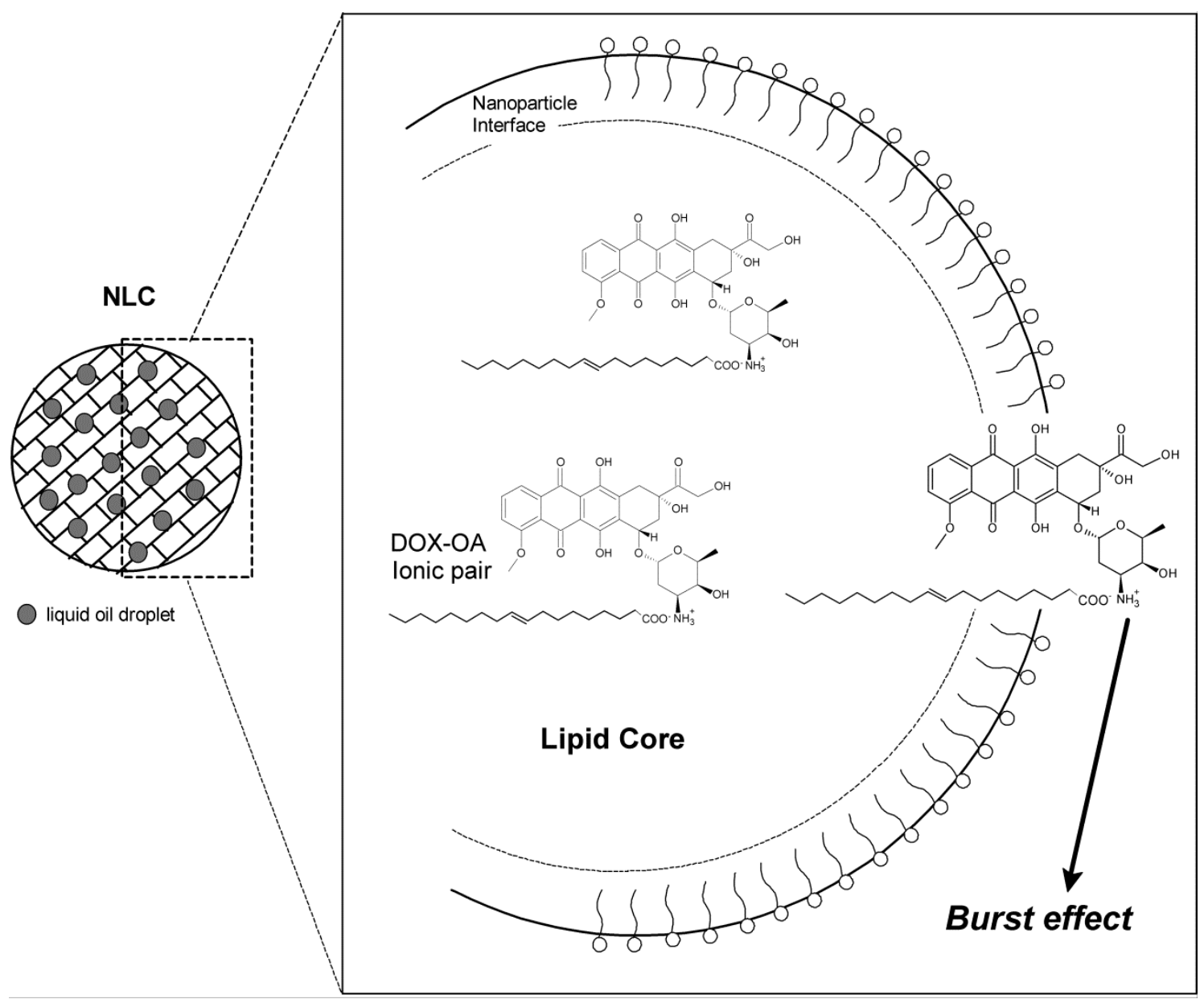

Figure 7. Scheme of the NLC loaded with doxorubicin as an ionic pair with oleic acid (DOX-OA ionic pair) and DHA (represented by a liquid oil droplet). The burst effect seen in the release assay may be explained by presence of a fraction of? the part of the ionic pair that is possibly located in the nanoparticle interface. 
Supplementary data, should be referred though text

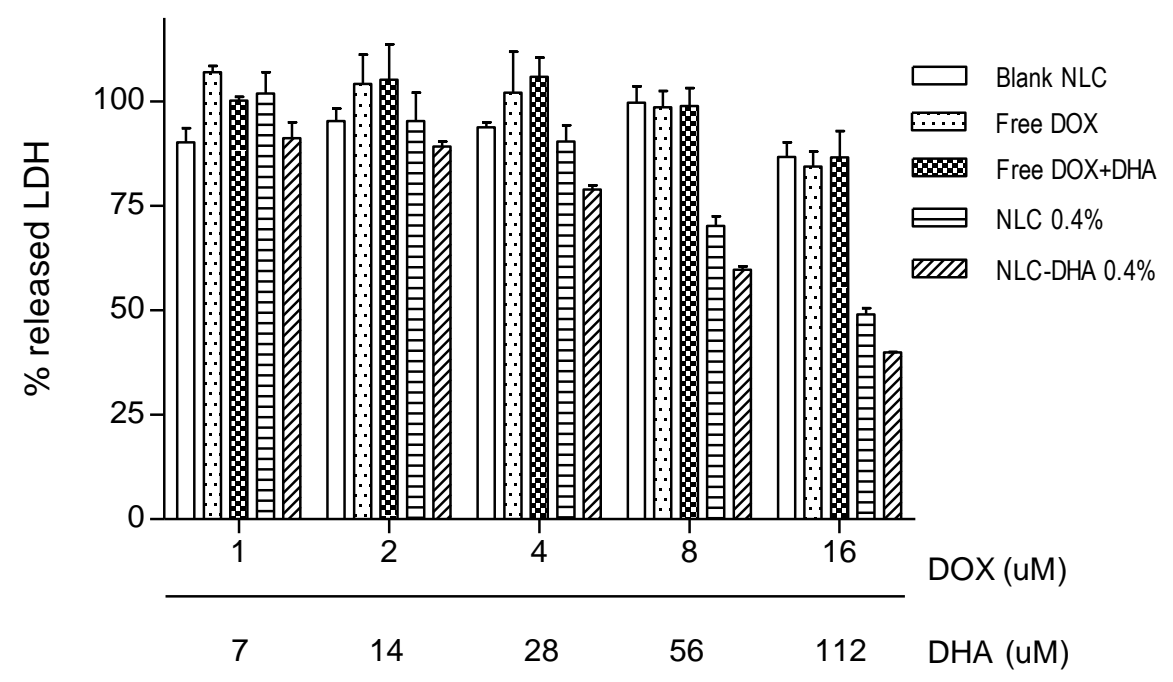

Figure A. Cytotoxicity blank formulation (Blank NLC), free doxorubicin (Free DOX), free doxorubicin + DHA (Free DOX+DHA), doxorubicin-loaded NLC (NLC 0.4\%) and doxorubicin + DHA-loaded NLC (NLC-DHA 0.4\%) in against MCF-7/Adr monolayer after $24 \mathrm{~h}$ of incubation, evaluated by Cytotox 96 cell viability kit (Promega). $\mathrm{N}=3$; Averages $\pm \mathrm{SD}$.

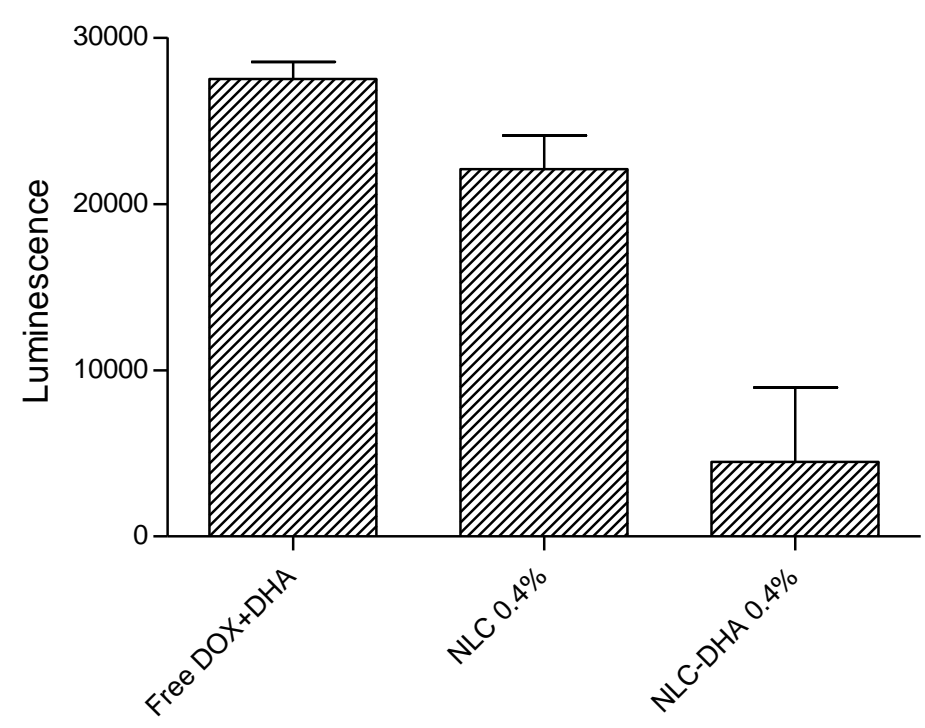

Figure B. Toxicity of free doxorubicin+DHA (free DOX+DHA), doxorubicin loaded in NLC (NLC 0.4\%) and doxorubicin + DHA loaded in NLC (NLC-DA $0.4 \%$ ) in against MCF-7/Adr spheroids, after $48 \mathrm{~h}$ of incubation with $100 \mu \mathrm{M}$ of doxorubicin before determination of ATP with a Cell Titer Glo luminescence assay (Promega). The levels of ATP after lysis of spheroids with $0.9 \%$ TritonX100 were measured by luminescence. 